Patients with Liver Disease.-Three non-acidotic patients with severe liver disease were tested with small amounts of sodium acetate intravenously $(100 \mathrm{ml}$. containing $89.2 \mathrm{mEq}$ of acetate). One suffered from cirrhosis, one from chronic hepatitis with splenomegaly, and the third from acute severe jaundice following prolonged extracorporeal circulation for cardiac surgery. All three had high serum bilirubin levels $(11-12.9 \mathrm{mg} / 100 \mathrm{ml}$.$) and high transaminase levels (168,240$, and 1,370 units respectively). In all three there was a significant increase in $\mathrm{pH}$ and total $\mathrm{CO}_{2}$. The mean rise in $\mathrm{pH}$ was 0.093 and the mean rise in total $\mathrm{CO}_{2}$ was $3.06 \mathrm{mM} / 1$.

\section{Discussion}

The results obtained in correcting acidosis due to uraemia in this study compare favourably with those obtained by Cash et al. (1969) and Watten et al. (1969) in acute acidosis caused by cholera. Thus our study further confirms the conclusions reached by these authors that acetate-containing solutions can be used as an alternative to solutions containing bicarbonate. In a preliminary study of three patients with liver disease acetate solutions have also proved effective in raising the blood $\mathrm{pH}$ and total $\mathrm{CO}_{2}$. There were no significant changes in the serum osmolality, serum electrolytes, and blood pressure of the patients with the doses used.

The ready availability of sodium acetate and the ease of its preparation obviously make its use practicable when it is needed in large quantities for the treatment of many patients simultaneously.

Our thanks are due to our biochemists, Messrs. R. Sylten and Y. Nakash, who performed the biochemical determinations.

\section{REFERENCES}

Boen, S. T., Mion, C. M., Curtis, F. K., and Shilipetar, G. (1964). Transactions. American Society for Artificial Internal Organs, 10, 409.

Cash, R. A., Toha, K. M. M., Nalin, D. R., Huq, Z., and Phillips, R. A. (1969). Lancet, 2, 302

Earnest, D. L., Sadler, J. H., Ingram, R. H., and Macon, E. J. (1968). Transactions. American Society for Artificial Internal Organs, 14, 434. Mion, C. M., Hegstrom, R. M., Boen, S. T., and Scribner, B. H. (1964) Transactions. American Society for Artificial Internal Organs, 10, 110. Mudge, G. H., Manning, J. A., and Gilman, A. (1949). Proceedings of the Society for Experimental Biology and Medicine, 71, 136.

Richardson, J. A., and Borchardt, K. A. (1969). British Medical fournal, 3, 749.

Schwartz, W. B., and Waters, W. C. (1962). American fournal of Medicine, 32,831

Watten, R. H., Gutman, R. A., and Fresh, J. W. (1969). Lancet, 2, 512.

\title{
Spironolactone Diuresis in Patients with Cirrhosis and Ascites
}

\author{
RONALD C. EGGERT,* M.D.
}

\begin{abstract}
Summary: Increased aldosterone levels with consequent $S$ or diuretic-potentiated electrolyte abnormalities are an important consideration when patients with cirrhosis and ascites undergo diuresis. A simple clinical method using the urinary $\mathrm{Na} / \mathrm{K}$ ratio as a guide to spironolactone dosage is outlined. Patients with a ratio greater than 1 responded well to $100 \mathrm{mg}$. of spironolactone a day; those when it was one or less responded well to 200 to 1,000 mg. a day.
\end{abstract}

Administration of spironolactone alone (11 patients) or as the main diuretic (three patients) was a safe and effective means of inducing sustained uncomplicated diuresis in all these patients.

\section{Introduction}

Most patients with cirrhosis and ascites have increased aldosterone secretory rates (Coppage et al., 1962; Ames et al., 1965) which vary considerably from patient to patient. Decreased hepatic inactivation of aldosterone has also been found in cirrhotics (Coppage et al., 1962). These factors cause increased effective aldosterone levels and often lead to sodium retention and appreciable potassium depletion (de Deuxchaisnes et al., 1961; Casey et al., 1965). Further potassium depletion occurs if thiazides or more potent natriuretic agents are given, as these drugs increase the amount of sodium presented to the distal tubule where increased aldosterone levels facilitate the exchange of sodium for potassium; severe electrolyte disturbances may result and may be related to the development of hepatic encephalopathy (Lieberman and Reynolds, 1965; Sherlock et al., 1966).

The spirolactones are competitive inhibitors of mineralocor* Instructor in Medicine, Department of Medicine, University of Minnesota
Hospitals, Minneapolis, Minnesota 55455 . ticoids (Liddle, 1957). In human studies their natriuretic and potassium-retaining effects can be titrated against the level of circulating mineralocorticoid, the urinary $\mathrm{Na} / \mathrm{K}$ ratio being used as a guide to effectiveness (Ross, 1962). In most clinical studies of diuresis in patients with cirrhosis fixed and relatively small doses of spirolactones usually combined with other types of diuretics have been used (Gantt and Ecklund, 1962; Sherlock et al., 1966). If we assume wide variations in aldosterone secretory rates in such patients with ascites, it is reasonable to expect a varying requirement for an aldosterone antagonist during diuresis.

This study was undertaken to assess the value of spironolactone in the treatment of ascites in cirrhosis, the urinary $\mathrm{Na} / \mathrm{K}$ ratio being used to titrate individual dose. The design was simplified so that it could be conveniently and inexpensively applied in varying clinical situations. Another objective was to use measures, particularly diet, to which the patients could easily adhere after discharge.

\section{Patients and Methods}

Fourteen patients with cirrhosis due to chronic alcoholism and persistent ascites were admitted to the general medical wards of the University of Minnesota Hospitals or the St. Paul-Ramsey Hospital. The diagnosis of cirrhosis was based on history, physical examination, and laboratory tests of hepatic function and was confirmed in six cases by liver biopsy.

The patients were observed in hospital for 3 to 54 days before beginning the diuretic regimen. Serious complications, such as infection or haemorrhage, were not present at the time diuresis was undertaken. The patients were maintained on bed rest and weighed daily. The daily diet was not rigidly controlled and contained 45-90 mEq of sodium and 40-80 $\mathrm{mEq}$ of potassium. Fluid was restricted to 1 litre per day. Twenty-four-hour urine samples were collected daily until 
adequate diuresis was established and analysed for sodium and potassium. Venous blood was analysed often for sodium, potassium, chloride, bicarbonate, haemoglobin, differential white count, liver functions, and serum urea nitrogen. Except for diagnostic removal of small amounts of ascites, paracentesis was not performed.

If the initial urinary $\mathrm{Na} / \mathrm{K}$ ratio was greater than one, the patient was placed on 100 or $150 \mathrm{mg}$. of spironolactone per day in divided doses at six-hour intervals. If the initial urinary $\mathrm{Na} / \mathrm{K}$ ratio was less than one, spironolactone was begun at 200 or $300 \mathrm{mg}$. per day. Thereafter, at intervals of two to four days the daily dose was increased by 100 or 200 mg. until the urinary $\mathrm{Na} / \mathrm{K}$ ratio became greater than one. If diuresis did not ensue within three to four days after the ratio reversed, ethacrynic acid or frusemide was added in increasing amounts until diuresis occurred. Potassium supplements were not administered during spironolactone therapy; several patients received supplements before diuretic therapy.

\section{Results}

On the basis of initial urinary electrolyte excretion, the patients were divided into two groups: those with $\mathrm{Na} / \mathrm{K}$ ratio greater than one (group 1) and those with a ratio of one or less than one (group 2). Group 2 was further divided into patients who had a diuresis with spironolactone alone (group $2 \mathrm{a}$ ) and those who required an additional diuretic (group $2 \mathrm{~b}$ ). The results are shown in the Table.

\section{Group 1 (Cases 1-3)}

During the initial observation period two patients lost no weight and one patient lost $1 \mathrm{lb}$. $(0.45 \mathrm{~kg}$.) in three days. Hyponatraemia was noted in two patients, hypokalaemia in two, and hypochloraemia in one. These patients responded uniformly well to small doses of spironolactone $(100-150 \mathrm{mg}$.) with increased sodium output and rapid, large diureses (22-57 lb.; 9.9-25.8 kg.). Diuresis began within 48 hours of onset of therapy and continued until ascites was no longer present. Hypokalaemia was corrected during diuresis. High normal serum potassium was observed in Case 3. Only mild and clinically insignificant abnormalities of sodium, chloride, and/ or bicarbonate were noted in all during diuresis. One patient (Case 2) was in hepatic precoma (depressed consciousness and asterixis) during the initial observation period and this cleared during the first several days of diuresis.

\section{Group 2a (Cases 4-11)}

During the initial observation period three patients lost no weight, three gained, and two lost small amounts. Hyponatraemia and hypokalaemia were observed in six patients, abnormal bicarbonate in three, and abnormal chloride in five. The dose of spironolactone required to reverse the $\mathrm{Na} / \mathrm{K}$ ratio varied from 200 to $1,000 \mathrm{mg}$. per day. Diuresis (total 14$31 \mathrm{lb}$; $6 \cdot 3-14.1 \mathrm{~kg}$.) regularly began within 72 hours after the ratio had reversed and continued until ascites was no longer demonstrable. During diuresis one or more slight to moderate, but clinically insignificant, abnormalities of serum sodium, chloride, or bicarbonate occurred at least once in each patient. In every instance intitial hypokalaemia was corrected and hypokalaemia did not occur during diuresis. Comparison of initial and post-diuresis electrolytes showed either overall improvement or no essential change in each case. Case 4 had hepatic encephalopathy initially; this cleared as diuresis progressed.

\section{Group 2b (Cases 12-14)}

Insignificant or no weight loss occurred during the observation period. Hyponatraemia was present in two patients, hypokalaemia in one, and hypochloraemia and raised bicarbonate in all. Spironolactone was administered until the urinary $\mathrm{Na} / \mathrm{K}$ ratio became greater than one; when no diuresis ensued frusemide or ethacrynic acid was added. Good diuresis (24-26 lb.; 10.9-11.8 kg.) then occurred in all. Hyponatraemia occurred in all cases and further chloride depression in Case 12. Serum potassium was slightly depressed on 3 out of 11 measurements in Case 14. The initially abnormal chloride and bicarbonate values reverted to or toward normal in Cases 13 and 14. Mild hyperkalaemia occurred in Case 13 and responded to a $100-\mathrm{mg}$. reduction in daily spironolactone dose. During the control period Case 14 was in hepatic precoma, which gradually cleared during diuretic therapy.

\section{Complications}

Mild hyperkalaemia unaccompanied by clinical or electrocardiographic signs occurred after complete diuresis in Cases 3 and 11 and during diuresis in Case 13. The medication was discontinued in Case 3 and continued at reduced dosage in Cases 11 and 13. Case 11 subsequently received

Serum and Urine Electrolytes Before, During, and After Diuresis, Diuretics, and Weights

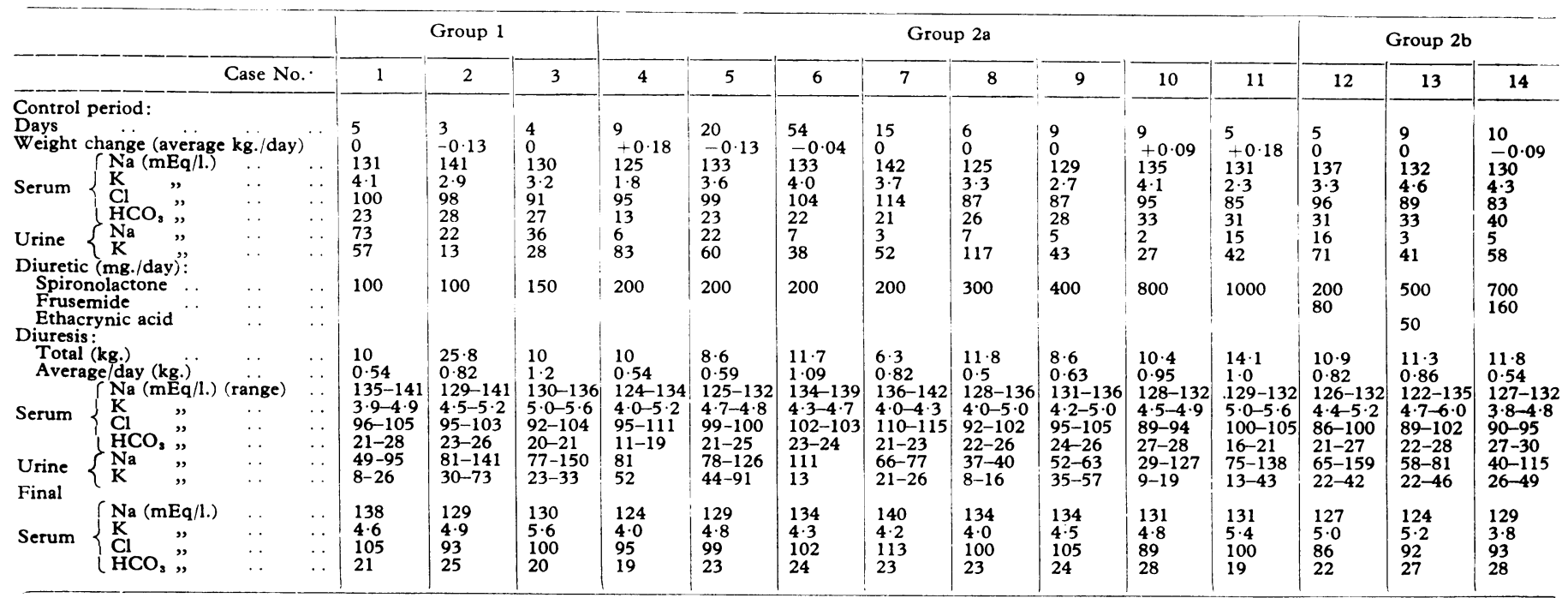


spironolactone for 18 months without untoward effect or reaccumulation of ascites. The serum urea nitrogen was raised during intitial observation in two patients; in both it was normal at the end of diuresis and did not rise in any patient during diuresis. Liver function studies remained stable or improved during the stay in hospital.

Two women and one man (Cases 10,11, and 13) reported breast tenderness, but it was not severe enough to warrant discontinuing spironolactone. One patient (Case 10) who had a previous history of coronary artery disease and atrial fibrillation died suddenly while receiving spironolactone one week after the diuresis reported here. Necropsy showed old and fresh myocardial infarction.

\section{Discussion}

A regimen for inducing diuresis by means of individually regulated doses of spironolactone in patients with cirrhosis and ascites was effective in all treated patients. Eleven out of 14 patients had a diuresis while receiving spironolactone alone; three required additional diuretics. Spironolactone did not induce the large rapid diuresis that may be seen with the more potent natriuretic agents, but this study clearly shows that its continued administration in proper dosage results in impressive cumulative diuresis. Clinically significant electrolyte abnormalities did not occur during diuresis, and preexisting abnormalities, particularly hypokalaemia, reverted to or toward normal during treatment. Hepatic encephalopathy did not occur during diuresis; three patients showed pretreatment encephalopathy which cleared during diuresis as the serum potassium returned to normal.

Sherlock et al. (1966) reported electrolyte abnormalities in $75 \%$ of 112 patients treated with several diuretic regimens, including one with a fixed dose of spironolactone: $38 \%$ had diuretic-induced hypokalaemia and $29 \%$ developed signs of hepatic encephalopathy. Potassium-sparing diuretics have been regarded as especially useful in preventing the hypokalaemia induced by more potent diuretics (Lavagh, 1967); nevertheless, and despite the known variation in aldosterone secretory rates, previous series have used relatively small and fixed doses of aldosterone antagonists (Ogden et al., 1961; Gantt and Ecklund, 1962; Sherlock et al., 1966). Though the number of patients in the present series is small, the avoidance of hypokalaemia and hepatic encephalopathy is consistent and unique, suggesting that a diuretic programme including individualized dosages of aldosterone antagonist may be a more appropriate regimen for inducing diuresis in patients with secondary hyperaldosteronism. In those patients with pretreatment hypokalaemia reduction of potassium loss plus adequate dietary intake were sufficient to correct serum potassium deficit and supplementary potassium was not required.
Mild hyperkalaemia occurred in two patients after diuresis and suggests that in those patients requiring maintenance therapy a lower dose of spironolactone than that which induced diuresis may suffice.

The aldosterone secretory rates were not measured in these patients. The wide range of spironolactone dose required to reverse the urinary $\mathrm{Na} / \mathrm{K}$ ratio, however, agrees with the observed wide variation of aldosterone secretory rates in patients with cirrhosis (Ames et al., 1965). Hence probably the dose of spironolactone required to effect reversion of the urinary $\mathrm{Na} / \mathrm{K}$ ratio reflects the degree of secondary aldosteronism. The possible contributions of impaired drug absorption or accelerated drug inactivation or excretion in such patients have not been evaluated.

Spontaneous natriuresis and diuresis in patients with cirrhosis and ascites have been reported (Pecikyan et al., 1967). The Table shows that 10 patients had no weight change or weight increase during the initial observation period. Four patients lost weight during this period, but the weight loss was small compared with that which occurred during the treatment period. The diuresis consistently began within 48 to 72 hours after increased natriuresis (group 1), after reversal of $\mathrm{Na} / \mathrm{K}$ ratio (group 2a), or within several hours after frusemide or ethacrynic acid had been given to patients in whom the $\mathrm{Na} / \mathrm{K}$ ratio had been corrected with spironolactone (group 2b). For these reasons it seems unlikely that spontaneous diuresis was a significant factor in these patients.

I am indebted to the University of Minnesota Hospitals and St. Paul-Ramsey Hospital house-staff members who allowed patients under their care to participate and to Dr. D. B. Hunninghake for helpful comments during the preparation of the manuscript.

\section{REFERENCES}

Ames, R. P., Borkowski, A. J., Sicinski, A. M., and Laragh, J. H. (1965). Fournal of Clinical Investigation, 44, 1171.

Casey, T. H., Summerskill, W. H. J., and Orvis, A. L. (1965). Gastroenterology, 48, 198.

Coppage, W. S., Island, D. P., Cooner, A. E., and Liddle, G. W. (1962) Fournal of Clinical Investigation, $41,1672$.

de Deuxchaisnes, C. N., Collet, R. A., Busset, R., and Mach, R. S. (1961) Lanct, 1, 681. Gant, C. L., and Ecklund, R. E. (1962). American fournal of Medicine, 33,

Laragh, J. H. (1967). Annals of Internal Medicine, 67, 606.

Liddle, G. W. (1957). Science, 126, 1016.

Lieberman, F. L., and Reynolds, T. B. (1965). Gastroenterology, 49, 531.

Ogden, D. A., Scherr, L., Spritz, N., and Rubin, A. L. (1961). New England Fournal of Medicine, $265,358$. Pecikyan, R., Kanzaki, G., and Berger, E. Y. (1967). American fournal of
Medicine, 42, 359.

Ross, E. J. (1962). Clinical Science, 23, 197. Sherlock, S., Senewiratne, B., Scott, A., and Walker, J. G. (1966). Lancet
1, 1049 . 